\title{
FETOMATERNAL OUTCOME IN PATIENTS WITH PREVIOUS ONE LOWER SEGMENT CESAREAN SECTION, COMPLICATIONS WITH REPEAT SCAR AND TRIAL OF SCAR.
}

\footnotetext{
1. MBBS, MCPS, FCPS Senior Registrar Department of Gyne\&Obs DHQ Teaching Hospital Rawalpindi, Rawalpindi Medical University Rawalpindi.

2. MBBS, MCPS, FCPS

Consultant

Department of Gyne\&Obs Nesom Hospital Islamabad.

3. MBBS, MCPS, FCPS Associate Professor and Head Department of Gyne\&Obs Medical College Mirpur Azad Kashmir.
}

Correspondence Address:

Dr. Asma Batool

House No.96, Street 14

Gulraiz Phase-2, Rawalpindi

drasmafaisal@yahoo.com

Article received on:

17/10/2018

Accepted for publication: 09/03/2019

Received after proof reading:

$30 / 09 / 2019$

\begin{abstract}
Asma Batool', Mussarat Sultana ${ }^{2}$, Saima Perveen ${ }^{3}$
ABSTRACT... Objectives: The aim of our study is to see the maternal and fetal outcome of pregnancies with previous one lower segment cesarean section. Study Design: Prospective study. Setting: Department of obstetrics and gynecology at DHQ Teaching Hospital Rawalpindi. Period: $1^{\text {st }}$ January 2018 to $31^{\text {st }}$ June 2018 . Material and Methods: All pregnant women with previous one LSCS and at the gestation of more than 34 week are included after taking consent. Results: 258 patients were included. 132(51.2\%) had elective LSCS, 106(41\%) had emergency LSCS. $77(29.8 \%)$ patients actually took trial of scar, $20(25.9 \%)$ patients delivered vaginally. $179(69.8 \%)$ patients had no maternal morbidity. 3(1.2\%) patients had peripartum hysterectomy secondary to PPH due to placenta previa. The most common indication for emergency LSCS was fetal distress. The second commonest indication was failure to progress in first stage of labour. 248 (96.1\%) of our neonates had good APGAR score(>7 at one minute). We had very low rate for NICU admission, only 10(3.9\%) neonates were admitted to NICU. 4 neonates were premature, 5 neonates were admitted due to low birth weight and one with fetal hypoxia. Conclusion: Rate of repeat LSCS is increasing on maternal demand and fetal distress, by careful selection of the patients for VBAC, proper counseling and advanced facilities for monitoring of fetus, repeat LSCS rate can be decreased with associated decrease in maternal and perinatal morbidity and mortality. Comfortable environment and tender loving care during first delivery can decrease the number of patients with refused trial of labour.
\end{abstract}

Key words: Lower Segment Cesarean Section (LSCS), Outcome, Vaginal Birth after LSCS.

Article Citation: Batool A, Sultana M, Perveen S. Fetomaternal outcome in patients with previous one lower segment cesarean section, complications with repeat scar and trial of scar. Professional Med J 2019; 26(10):1600-1605. DOI: 10.29309/TPMJ/2019.26.10.217

\section{INTRODUCTION}

The acceptable cesarean delivery rate is still debatable. Delivery after previous one LSCS is a great challenge in present day obstetrics. The overall caesarean section is increasing worldwide. The caesarean section rate has been increased from $5 \%$ to $35 \%$ in the last 40 years. There is a consensus between $\mathrm{NICE}^{1}, \mathrm{RCOG}^{2}, \mathrm{ACOG}^{3}$ and $\mathrm{NIH}$ that with a single previous LSCS planned vaginal birth is a safe option. There are certain risks associated with VBAC. These include fetal anoxia, fetal death, admission in NICU, uterine scar dehiscence, uterine rupture, placenta previa, placenta accrete, hemorrhage and later on wound infection. There are certain risk factors which increase the complication rate in VBAC. These include short inter pregnancy interval(less than one year), postdates pregnancy, poor bishop score, obesity and maternal age more than 40 years. ${ }^{4,5}$

Trial of the scar is a great challenge for obstetrician in a low resource setting, because of the risk of uterine dehiscence, failed trial of scar, uterine rupture leading to hemorrhage and fetal death. With careful assessment of women who opt for trial of scar and continuous intensive fetomaternal monitoring during labour the complication rate is around $2 \%$.

Counseling of the women and her partner about risks and benefits of repeat elective caesarean, emergency caesarean in case of failed trial of scar and VBAC should be done and a plan of mode of delivery should be documented on antenatal notes. 
With careful assessment the success rate of VBAC is from $30-70 \%$ depending upon indication of previous caesarean and current status of the mother and baby. However there is increasing trend of decreasing acceptability for trial of scar in women. Trial of scar can reduce repeat caesarean rate considerably.

Our study accesses the mode of delivery ,indication of repeat LSCS, maternal complications in terms of hemorrhage, blood transfusion, intraabdominal adhesions, peripartum hysterectomy, wound infection and fetal outcome in women with previous one caesarean in terms of APGAR score, weight of the baby, admission in NICU.

\section{MATERIAL AND METHODS}

This prospective study was conducted at DHQ Teaching Hospital Rawalpindi between 1st January 2018 to $31^{\text {st }}$ June 2018 . Ethical approval from local ethical committee was taken. We included all women with previous one LSCS and at a gestation of more than 34 weeks who came to DHQ hospital. We excluded the patients with previous one scar and gestational age less than 34 weeks, previous two or more than two scar and pregnancy with previous classical caesarean section. Detailed history was taken regarding demographic details, past obstetrical history, indication of previous caesarean, antenatal, intrapartum, postpartum complications, gestation of delivery, place of delivery, and weight of the baby. Detailed history about current pregnancy regarding her last menstrual period, her dating scan, past medical and surgical history and socioeconomic history was also taken. Detailed general physical and obstetrical examination was done, counseling of the woman and her partner was done at 36 weeks regarding risks and benefits of elective versus emergency LSCS and VBAC. Assessment for feasibility of vaginal delivery was done at 37 weeks, Plan of birth and consent of the patient was documented in antenatal note. Women who were non-booked and came in emergency, were accessed at the time of presentation.

The women who were not fit for trial of scar, refused trial of scar or had any medical problem like PIH, DM etc. were admitted in antenatal ward at $38+$ weeks, steroid cover given regarding fetal lung maturity and elective LSCS done at 38+ weeks. Those women who were willing for trial of scar were cared on OPD basis. They waited for spontaneous onset of labour till 40 weeks, if they go in spontaneous labour trial of scar was given if they did not go in spontaneous labour, elective LSCS was done. We did not allow the women to go postdates. We are not doing induction of labour in women with previous caesarean section due to increased risk of complications and lack of extensive monitoring facilities in our hospital.

The woman who went in spontaneous labour, all preparation for emergencys LSCS, blood transfusion and neonatal care were made. All the patients were observed for complications like blood transfusion, PPH, hematoma formation, and sepsis. Neonates were observed regarding APGAR score, weight of the neonate, admission in NICU and perinatal mortality.

Women with successful VBAC were discharged after 24 hours and women with repeat scar were discharged on $3^{\text {rd }}$ post-operative day, called back on $7^{\text {th }}$ post-operative day for stitch removal.

\section{RESULTS}

During study period a total of 3560 women delivered in DHQ hospital. 258(7\%) patients had previous one scare who were included in our study, 92(35.6\%) were not suitable for trial of scar, $166(64.4 \%)$ were suitable for trial of scar but $58(22.5 \%)$ refused trial of scar.

So 108 (41.9\%) were willing for trial of scar. Out of these 108 patients 22 became postdates so elective LSCS done for them, rest of the 86 patients went in spontaneous labour and out of them $9(10.5 \%)$ patients refused trial of scar during labour, remaining $77(29.8 \%)$ patients actually took trial of scar, $20(25.9 \%)$ patients delivered vaginally, rest of the $57(74.1 \%)$ patients had emergency LSCS due to different indications. The commonest indication for emergency LSCS was fetal distress. The second commonest indication was failure to progress in first stage of labour. Regarding elective LSCS the most 
common indication was refused trial of scar, $67(26 \%)$ patients refused trial of scar. Although these patients were fit for trial but they refused. Oligohydromnios was the second most common cause of elective LSCS. 15(5.8\%) patients had repeated elective LSCS followed by the breech presentation 14(5.4\%).

In our study $179(69.4 \%)$ patients had no morbidity, 32(12.4\%) patients had adhesions with anterior abdominal wall, omentum, bowel or bladder, $13(5 \%)$ patients had scar dehiscence without labour, 8(3.1\%) patients need blood transfusion and $3(1.2 \%)$ patients had peripartum hysterectomy due to placenta previa leading to $\mathrm{PPH}$. 6(2.3\%) patients had wound infection at $4^{\text {th }}$ post-operative day and another $4(1.2 \%)$ got puerperal pyrexia.

In our study $131(50.8 \%)$ were female babies and $127(49.2 \%)$ were male babies.226 (87.6\%) has birth weight between $2.5 \mathrm{~kg}-3.5 \mathrm{~kg} .25$ (9.7\%) babies were low birth weight and $2(0.8 \%)$ babies has birth weight $>4 \mathrm{~kg}$.

In our study 248(96.1\%) were with good APGAR score,6(2.3\%) babies born with poor APGAR score and they were resuscitated. 4 (1.6\%) babies delivered with no signs of life. they were diagnosed before birth and had no identifiable cause for their death.

In our study only $10(3.9 \%)$ babies needed NICU care 3 of them were preterm and rests of them were with low birth weight.

\begin{tabular}{|c|c|c|c|c|}
\hline Mode of Delivery & Frequency & Percent & Valid Percent & Cumulative Percent \\
\hline VBAC & 20 & 7.8 & 7.8 & 7.8 \\
\hline Emergency Iscs & 106 & 41.1 & 41.1 & 48.8 \\
\hline Elective Iscs & 132 & 51.2 & 51.2 & 100.0 \\
\hline Total & 258 & 100.0 & 100.0 & \\
& & Table-I. Mode of delivery &
\end{tabular}

\begin{tabular}{|l|c|c|c|c|}
\hline \multicolumn{1}{|c|}{ Indication for repeat LSCS } & Frequency & Percent & Valid Percent & Cumulative Percent \\
\hline breech & 20 & 7.8 & 7.8 & 7.8 \\
\hline IUGR & 14 & 5.4 & 5.4 & 13.2 \\
\hline twins & 4 & 1.6 & 1.6 & 14.7 \\
\hline Post dates & 2 & .8 & .8 & 15.5 \\
\hline Abruptioplacenta & 22 & 8.5 & 8.5 & 24.0 \\
\hline PIH & 3 & 1.2 & 1.2 & 25.2 \\
\hline Fetal distress & 26 & 10.1 & 10.1 & 35.3 \\
\hline failure to progress in first stage of labour & 34 & 13.2 & 13.2 & 48.4 \\
\hline failure to progress in second stage of labour & 15 & 5.8 & 5.8 & 54.3 \\
\hline oligohydromnios & 20 & 7.8 & 7.8 & 62.0 \\
\hline scar tenderness positive & 15 & 5.8 & 5.8 & 67.8 \\
\hline refused trial of scar & 9 & 3.5 & 3.5 & 71.3 \\
\hline Placenta previa & 67 & 26.0 & 26.0 & 97.3 \\
\hline Total & 7 & 2.7 & 2.7 & 100.0 \\
\hline
\end{tabular}

Table-II. Indication for repeat LSCS 


\begin{tabular}{|l|c|c|c|c|}
\hline Complications with repeat LSCS & Frequency & Percent & Valid Percent & Cumulative Percent \\
\hline No complication & 179 & 69.4 & 69.4 & 69.4 \\
\hline scar dehiscence & 13 & 5.0 & 5.0 & 74.4 \\
\hline blood transfusion & 8 & 3.1 & 3.1 & 77.5 \\
\hline Tears extending in lower segment & 7 & 2.7 & 2.7 & 80.2 \\
\hline adhesions with omentum, bowel ,bladder or & 32 & 12.4 & 12.4 & 92.6 \\
\hline anterior abdominal wall & 3 & 1.2 & 1.2 & 93.8 \\
\hline peripartum hysterectomy & 2 & .8 & .8 & 94.6 \\
\hline complications of anesthesia & 5 & 1.9 & 1.9 & 96.5 \\
\hline PPH & 3 & 1.2 & 1.2 & 97.7 \\
\hline puerperal pyrexia & 6 & 2.3 & 2.3 & 100.0 \\
\hline wound infection & 258 & 100.0 & 100.0 & \\
\hline Total & -11.0 & & \\
\hline
\end{tabular}

Table-III. Maternal morbidity

\begin{tabular}{|l|c|c|c|c|}
\hline Sex of the Babies & Frequency & Percent & Valid Percent & Cumulative Percent \\
\hline Female & 131 & 50.8 & 50.8 & 50.8 \\
\hline Male & 127 & 49.2 & 49.2 & 100.0 \\
\hline Total & 258 & 100.0 & 100.0 & \\
\hline
\end{tabular}

Table-IV. Fetal outcome

\begin{tabular}{|l|c|c|c|c|}
\hline Weight of the Babies & Frequency & Percent & Valid Percent & Cumulative Percent \\
\hline$<2.5 \mathrm{~kg}$ & 25 & 9.7 & 9.7 & 9.7 \\
\hline $2.5-3.5 \mathrm{~kg}$ & 226 & 87.6 & 87.6 & 97.3 \\
\hline $3.5-4 \mathrm{KG}$ & 5 & 1.9 & 1.9 & 99.2 \\
\hline$>4 \mathrm{~kg}$ & 2 & .8 & .8 & 100.0 \\
\hline Total & 258 & 100.0 & 100.0 & \\
\hline
\end{tabular}

Table-V. Weight of the babies at birth

\begin{tabular}{|l|c|c|c|c|}
\hline \multicolumn{1}{|c|}{ APGAR Score of the Babies } & Frequency & Percent & Valid Percent & Cumulative Percent \\
\hline Good(7/10) & 248 & 96.1 & 96.1 & 96.1 \\
\hline poor, needs resuscitation(<7/10) & 6 & 2.3 & 2.3 & 98.4 \\
\hline iud & 4 & 1.6 & 1.6 & 100.0 \\
\hline Total & 258 & 100.0 & 100.0 & \\
\hline
\end{tabular}

Table-VI. Apgar score of the babies

\begin{tabular}{|l|c|c|c|c|}
\hline Admission in NICU & Frequency & Percent & Valid Percent & Cumulative Percent \\
\hline Yes & 10 & 3.9 & 3.9 & 3.9 \\
\hline No & 248 & 96.1 & 96.1 & 100.0 \\
\hline Total & 258 & 100.0 & 100.0 & \\
\hline
\end{tabular}

Table-VII. Admission in NICU

\section{DISCUSSION}

Women with previous one lower segment caesarean section is a high risk population both antenatally and during labour. Decision about trial of labour or elective repeat lower segment caesarean section is on individual basis and need careful counseling of the couple. ${ }^{12}$ In our study 258 cases with previous one scar were included,
$77(29.8 \%)$ cases were given trial of scar and $20(25.9 \%)$ cases had successful VBAC as against $39.9 \%$ of the patients by landon et al and $64 \%$ cases in a study by Gonen and their colleagues. ${ }^{6}$ This low rate in our study is due to the reason that we are not inducing or augmenting labours with previous scar. The proportion of women undergoing trial of scar is decreasing day by day. This may be due to fear of complications, 
increased litigation in obstetrics and due to suboptimal monitoring facilities in some units. Sometimes obstetrician is sued for not doing a caesarean section. ${ }^{7}$

An Australian cohort study reported a VBAC rate of $59 \%(10)$, contrary to our study where VBAC success rate was $25.9 \%$. This difference may be because in our study we did not induce patients with previous scar and we have less monitoring facilities due to low resources. A large no of patients also refused trial of scar leading to low success rate of VBAC in our study.

We found that $106(41.1 \%)$ patients were delivered by em Iscs and the most common indication for em LSCS in our study was fetal distress, similar results were seen by Vardhan Shakthi et.at ${ }^{13}$, Shah Jitesh Mafatlal et.al' ${ }^{14}$ and Shruthi s Goel et.al. ${ }^{15}$

In our study we had $32(12.4 \%)$ cases with intraoperative adhesions, adhesions between uterus and anterior abdominal wall, bowel, bladder and omentum contrary to the study by Parikh et al, they found excessive adhesions $36 \%{ }^{8}$ There is increased morbidity and mortality with abdominal delivery as compared to vaginal delivery, along with low risk of uterine rupture in carefully selected patients for trial of scar $^{9}$ can decrease the high repeat LSCS rate. In our study $179(69.4 \%)$ cases had no morbidity.

Fetal outcome is better in our study we had 4 still births as compared to Zahid et al; they had 20still births in their study. ${ }^{11} 248$ (96.1\%) of our neonates had good APGAR score ( $>7$ at one minute). we have very low rate for NICU admission, only $10(3.9 \%)$ were admitted to NICU, 4 were premature, 5 babies were admitted due to low birth weight and one with fetal hypoxia.

67 (26\%) of our patients with previous one LSCS refused trial of scar. our results are not comparable with any study in this respect. The reasons were, our patients did not want to wait till 40 weeks. Most of the patients had painful experience during previous childbirth; they did not accept risk of failed VBAC followed by emergencys LSCS.
Patients wanted $100 \%$ success of VBAC which no obstetrician can give. However further studies are needed to evaluate the refusal of trial of labour.

\section{CONCLUSION}

The current study concludes that women with previous one LSCS are at increased risk of repeat scar, vigilance with respect to indication for primary scar, proper counselling for trial of labour and careful selection of the patients for VBAC can decrease the morbidity and mortality associated with LSCS. Our findings encourage obstetricians to further dig into the matter of refused trial of scar and to give tender loving care during first delivery. We may need to take psychological consultation for patients to evaluate their reason for refusal of scar, so that we can decrease the factors which bother these women and ultimately decrease the repeat LSCS rate. Further studies are needed to evaluate the indications of repeat scar and to decrease the repeat cesarean section rate.

\section{Copyright $@ 09$ March, 2019.}

\section{REFRENCES}

1. National institute for health and clinical excellence. Caesarean section. NICE clinical guideline 132. Manchester: NICE; 2011.

2. Royal College of Obstetricians and Gynaecologists. Birth after previous caesarean birth. Green-top Guideline No.45. London: RCOG; 2007.

3. American College of Obstetrician and Gynaecologists. ACOG Practice bulletin no.115: Vaginal birth after previous caesarean delivery. Obstet Gynnecol 2010; 116:450-63.

4. Barger MK, Weiss J, Nannini A, Werler M, Heeren T, Strubblefield PG, Risk factors for uterine rupture among women who attempt vaginal birth after previous caesarean: A case control study. J Reprod med 2011; 56:313-20.

5. Fitzpatrick KE, Kurinczuk JJ, Alfirevic Z, Spark P, Brocklehurst $P$, Knight $M$. Uterine rupture by intended mode of delivery in UK: A national case control study. PLos Med 2012; 9:e1001184.

6. Landon MB, Hauth JC, Leveno KJ, et al. Maternal and perinatal outcomes associated with a trial of labor after prior caesarean delivery. N Engl J Med. 2004; 351: 2581-2589. 
7. Landon MB, Hauth JC, Leveno KJ, et al. Maternal and perinatal outcomes associated with a trial of labor after prior caesarean delivery. $\mathrm{N}$ Engl J Med. 2004; 351: 2581-2589.

8. Parikh V. Management of patients with previous caesarean section. J Obstet and Gynaecol of India 1964; 14: 327.

9. Weinstein D, Benshushan. A, Tanos V, Zilberstien R, Rojansky N. Predictive score for vaginal birth after caesarean section. Am J Obstet \& Gynaecol 1996; 174: 192.

10. Crowther CA, Dodd JM, Hiller JE, Haslam RR, Robinson JS; Birth after Caesarean Study Group. Planned vaginal birth or elective repeat caesarean: Patient preference restricted cohort with nested randomized trial. PLoS Med 2012; 9:e1001192.
11. Zahid B, Khawaja N, Tayyab R. Obstetric outcome of cases referred to a tertiary care hospital after trial of labour. Ann KE Med Coll 2005; 11:289-91.

12. Shah SR, Prasad P. Outcome of labour in previous one lower segment cesarean section cases. Asian J Obstet Gynecol Pract 2006; 10:7-11.

13. Vardhan S, Behera RC, Sandhu GS, Singh A, Bandhu $\mathrm{HC}$. Vaginal birth after caesarean section: Analysis of indicators of success. J Indian Med Assoc 2006; 104:113-5.

14. Begum I, Khan A, Khan S, Begum S. Caesarean and Post Partum Hystrectomy. Pak J Med Res 2004; 43:134-7.

15. Shah JM, Mehta MN. Analysis of mode delivery in women with previous one caesarean section. J Obstet Gynecol India 2009; 59:136-9.

\begin{tabular}{|c|l|c|c|}
\hline \multicolumn{3}{|c|}{ AUTHORSHIP AND CONTRIBUTION DECLARATION } \\
\hline Sr. \# & Author-s Full Name & Contribution to the paper & Author's Signature \\
\hline 1 & Asma Batool & $60 \%$ & \\
\hline 2 & Mussarat Sultana & $20 \%$ & \\
\hline 3 & Saima Perveen & $20 \%$ & $\mathcal{L}$ \\
\hline
\end{tabular}

